\title{
Unasul e União Europeia: análise comparada em termos de segurança e defesa
}

\author{
Unasur and the European Union: comparative \\ analysis on security and defense issues
}

Rev. Bras. Est. Def. v. 7, $\mathrm{n}^{\circ} 1$, jan./jun. 2020, p. 67-96

DOI: $10.26792 /$ RBED.v7n1.2020.75198

ISSN 2358-3932

\section{TOMAZ ESPÓSITO NETO \\ LISA BELMIRO CAMARA}

\section{INTRODUÇÃO'}

As instituições regionais ocupam papel fundamental na construção da cooperação nos mais variados temas, entre eles a segurança e a defesa (Acharya 1994). Pensar esses organismos a partir de suas particularidades requer uma diferenciação entre as necessidades de cada região, o que, inevitavelmente, lhes confere dinâmicas de funcionamento próprias. Ao adicionar o componente da segurança e defesa, tal diferenciação torna-se ainda mais relevante, posta a fluidez daquilo que se entende como ameaça (Pagliari 2009), tanto no nível regional como no nível doméstico.

Neste contexto, com base no entendimento de que a comparação pode trazer ganhos singulares ao exercício investigativo, o presente trabalho - que compreende os anos entre 2008 e 2016 - traça um paralelo entre o Conselho de Defesa Sul-Americano (CDS) da União de Nações SulAmericanas (Unasul) e a Política Comum de Segurança e Defesa (PCSD) da União Europeia (UE). Para tanto foi escolhido o método comparado como ferramenta que permita responder à pergunta-guia desta investigação: por que a cooperação regional em segurança e defesa é uma inflexão?

\footnotetext{
Tomaz Espósito Neto - Professor Adjunto do Mestrado em Fronteiras e Direitos Humanos e do Curso de Relações Internacionais da FADIR / UFGD (Universidade Federal da Grande Dourados). Doutor em Ciências Sociais pela PUC-SP.

Lisa Belmiro Camara - Doutoranda em Relações Internacionais na Universidade Federal de Santa Catarina (UFSC). Bolsista da Coordenação de Aperfeiçoamento de Pessoal de Nível Superior (CAPES). Mestra em Fronteiras e Direitos Humanos na Universidade Federal da Grande Dourados (UFGD) e bacharela em Relações Internacionais pela mesma universidade. Pesquisadora visitante no Instituto Universitario de Investigación en Estudios Latinoamericanos da Universidad de Alcalá de Henares (UAH).
} 
Portanto, a proposta da comparação metodológica empregada como ponto-chave deste texto tem o objetivo de estabelecer a existência de padrões entre os processos de cooperação ocorridos em duas regiões distintas. Ao se considerar as diferenças marcantes entre as unidades estudadas, optou-se pelo método da comparação por diferenças de Przeworski e Teune (1970), que possibilita que a análise transite por mais de um nível e se encaixa na perspectiva de compreensão entre os interesses domésticos e regionais. Ademais, em termos teóricos, são definidos os conceitos de eficácia e potência regional.

Este artigo encontra-se dividido em quatro seções. No primeiro momento, o objetivo é situar metodologicamente a forma como está construída a comparação — já que tal método permite uma ampla variação em seu uso - , além de elucidar o conceito de eficácia utilizado para medir o funcionamento da PCSD e do CDS. Na sequência, as próximas três seções se dividem com base no quadro de comparação construído para a análise, e tratam, respectivamente, dos aspectos iniciais, institucionais e políticos referentes às unidades. Esta divisão tem a finalidade de tornar mais factível a proposta de comparação aqui pretendida, posto que são utilizadas oito categorias analíticas.

\section{VARIAÇÕES NO MÉTODO COMPARADO: A COMPARAÇÃO POR DIFERENÇAS}

Antes de entrar de fato no exercício comparativo entre a PCSD e o CDS, é importante explicitar o porquê da escolha deste método para o desenvolvimento da pesquisa. Sabe-se que nas ciências sociais e políticas o método comparativo é o substituto possível e imperfeito para o método experimental (Gonzalez 2007), pois, devido à impossibilidade de controle das variáveis, a comparação permite verificar quais fatores influenciam na reprodução ou não de um determinado padrão, algo que viabiliza inferências passíveis de derivarem em generalizações. Assim, a comparação é um recurso que permite a análise da multiplicidade de relações que permeiam os diferentes sistemas, sob diferentes níveis, e resulta em explicações mais completas e detalhadas no que diz respeito à interação entre as variáveis.

Neste sentido, parece ser produtivo o emprego do método comparativo quando se pretende evidenciar as semelhanças ou diferenças entre duas ou mais unidades de análise; contudo, há que se observar com cuidado outras possibilidades interessantes do uso deste método. Uma dessas possibilidades - e com a qual se trabalhou nesta investigação - reside no emprego da comparação para testar uma hipótese, de forma que seja possível compreender o elemento determinante para a explicação da variável dependen- 
te. Em suma: "si se quiere saber cuáles factores producen un determinado patrón en el comportamiento de una variable es mejor conducir una investigación basada en el diseño comparativo" (Villarroel 2001, 11).

Por conseguinte, cabe definir uma estratégia como caminho para a análise, que, no caso desta investigação, é o método da comparação pelas diferenças, ou most different systems (MDS), proposto por Przeworski e Teune (1970). O MDS possibilita uma comparação baseada em amostras de diferentes sistemas, permitindo que a análise possa transitar por mais de um nível. Segundo esses autores, a estratégia do MDS deve ser empregada quando fatores sistêmicos não são determinantes para prever os comportamentos em questão, ou seja, o nível sistêmico não é incorporado na análise. Logo, as variáveis independentes têm um papel fundamental nesta estratégia, pois, se a relação entre variáveis dependentes e independentes for a mesma nos sistemas estudados, significa que, de fato, o nível sistêmico não deve ser considerado na análise. Por essa razão, é possível afirmar que o desenho da comparação por diferenças está centrado na eliminação de fatores sistêmicos irrelevantes.

Ao considerar os componentes aqui estudados na tentativa de responder ao problema de pesquisa (pois trata-se de dois instrumentos distintos), o MDS oferece uma forma de comparação possível. Ademais, ainda que a Política Comum de Segurança e Defesa e o Conselho de Defesa Sul-Americano situem a análise no nível regional, é necessário avaliar o comportamento das potências regionais no nível doméstico, e isto resulta em uma análise de dois níveis que se encaixa no método da comparação pelas diferenças. $\mathrm{O}$ intuito desta comparação, cujas unidades de análise são dois diferentes instrumentos de cooperação institucionalizada em termos de segurança e defesa, é, portanto, deduzir quais fatores aparecem em comum nos dois sistemas que não permitem o aprofundamento desta cooperação. Logo, busca-se verificar pelas vias da comparação político-institucional a incidência das variáveis independentes, que são as potências regionais, na variável dependente, que é a cooperação regional em segurança e defesa.

Para se proceder com a comparação, foram designadas oito categorias analíticas para observar a variação nas unidades, a partir da formulação de Sartori (1994) sobre quais aspectos comparar. As categorias são: natureza, origem, longevidade, modelo institucional, estrutura, regra decisória, amplitude da agenda e dos objetivos e nível de convergência das potências regionais, e serão exploradas separadamente nos seguintes subtópicos deste trabalho. Além disso, para responder especificamente às inflexões observadas nos processos de cooperação em segurança e defesa, o conceito de eficácia, conforme empregado pela ciência política, oferece parâmetros 
para medir o grau destas inflexões, ao demonstrar se as instituições em questão são eficazes, conforme detalhado na próxima seção.

\section{Eficácia}

O raciocínio aqui desenvolvido, ao considerar a ótica dos institucionalistas, está inserido num debate que questiona até que ponto o desenho das instituições importa para determinar sua eficácia, e até que ponto o que define tal eficácia são fatores de cunho sócio-político (Acharya and Johnston 2007). Neste sentido, ao comparar duas instituições regionais de segurança e defesa, é necessário verificar o grau de eficácia de cada uma delas, como forma de compreender a inflexão no aprofundamento da cooperação. De acordo com a literatura que avalia as políticas públicas, há uma distinção entre eficácia, eficiência e efetividade, a depender da abordagem e do que se pretende avaliar. A eficácia mensura a relação entre os objetivos propostos e os alcançados, enquanto a eficiência relaciona o esforço no emprego de uma política e os resultados alcançados; já a efetividade avalia o sucesso ou fracasso na transformação social das populações atingidas por uma determinada política (Arretche 1998).

Conforme explicitado por Marta Arretche (1998, 5):

Por avaliação de eficácia entende-se a avaliação da relação entre os objetivos e instrumentos explícitos de um dado programa e seus resultados efetivos (Figueiredo and Figueiredo 1986). Esta avaliação pode ser feita entre, por exemplo, as metas propostas e as metas alcançadas pelo programa ou entre os instrumentos previstos para sua implementação e aqueles efetivamente empregados.

Ainda que na citação acima a autora se referisse a políticas públicas, é possível utilizar o conceito de avaliação de eficácia no âmbito institucional, considerando-se que as instituições têm objetivos e metas a serem cumpridos, conforme enunciado em seus documentos base e também via planos de ação (como é o caso do CDS) ou estratégias, (como no caso da PCSD). Portanto, o exercício de verificar as propostas estabelecidas nesses documentos e seu cumprimento ou não deve traçar um panorama a respeito da eficácia dessas instituições.

Ao se pensar a Política Comum de Segurança e Defesa desde sua implementação, pode-se afirmar serem poucos os instrumentos que permitem avaliar sua eficácia, pois a estratégia de ação mais recente data do ano de 2016. Ainda assim, vale o esforço de tal avaliação com base nos artigos do Tratado de Lisboa (2009) que dizem respeito exclusivamente à PCSD. Assim, ao se ter em vista o objetivo principal da PCSD, o qual visa tornar 
a UE um ator de segurança internacional com capacidade de atuação para além do âmbito civil, torna-se possível questionar até que ponto essa política tem sido de fato eficaz.

Em primeiro lugar está a dificuldade da PCSD em estabelecer um padrão justo de gastos com defesa mediante as divergências econômicas dos Estados-membros, algo que inevitavelmente confere mais poder a alguns Estados em detrimento de outros. Enquanto Estados como França e Reino Unido gastam respectivamente $1,8 \%$ e $1,9 \%$ de seu PIB com questões de defesa, países como Espanha (0,9\%) e Áustria (0,6\%) não chegam a empregar nem 1\% de seu PIB nesse setor. ${ }^{2}$ Este fator, por si só, representa um entrave na construção da ideia de um ator de segurança global, haja vista a necessidade de maior investimento para gerar maiores capacidades de defesa, o que deveria ocorrer de maneira a respeitar as especificidades econômicas dos países, mas sem deixar de lado a necessidade central de um maior financiamento em defesa. Logo, reaparece a problemática questão histórica da dificuldade da UE de falar com uma só voz, pois os maiores financiadores da defesa acabam por ter maior peso decisório sobre participar ou não de uma determinada missão, ou, ainda, sobre quais conflitos devem ser pensados como estratégicos para a atuação do bloco.

Neste sentido, a questão econômica, ainda que possa parecer secundária na análise da eficácia de uma política de defesa, acaba por definir as linhas de atuação da PCSD e, consequentemente, o poder decisório do órgão recai sobre os interesses daqueles atores que têm mais força econômica no interior da UE. Assim, é possível observar a incidência da variável independente - que é o interesse nacional das potências regionais - sobre a variável dependente — que é a cooperação regional em segurança e defesa —, pois ocorre um direcionamento no emprego da PCSD baseado nas prioridades de política externa de atores mais fortes, como França, Alemanha e Reino Unido $^{3}$ (Gaspar 2006).

Um segundo ponto a ser observado como determinante para pensar a pouca eficácia da PCSD diz respeito à quantidade de missões de cunho militar implementadas em detrimento daquelas de cunho civil, já que a finalidade principal da política aqui analisada é a de construir gradualmente uma identidade europeia em defesa (art. $42^{\circ}$ do Tratado da União Europeia [TUE]). O Relatório Anual de 2016, por exemplo, desenvolvido pelo Serviço Europeu para a Ação Externa, demonstra que, das 17 operações em curso naquele ano, apenas 6 eram de âmbito militar, conforme é possível observar no Quadro 1, ao passo que as demais contavam com capacidades civis. Este dado é importante pois demonstra, novamente, a dificuldade da UE em se estabelecer como um ator de peso em termos de segurança e defesa, posto que as capacidades civis da UE enquanto potência 
global não são questionáveis, e o objetivo da PCSD é justamente tornar a UE um ator de peso também em assuntos de defesa. Soma-se a esse entrave a pouca relevância estratégica das missões realizadas, caracterizadas por uma baixa ambição, além de serem planejadas com base em seus possíveis efeitos positivos ou negativos para a própria UE, em lugar de priorizar a necessidade das regiões vulneráveis (Bailes 2008; Menon 2014; Howorth 2017; Henriques and Silva 2019).

\section{Quadro 1}

Operações e missões militares em curso na UE

\begin{tabular}{|c|c|c|c|}
\hline $\begin{array}{l}\text { Operação/ } \\
\text { Missão }\end{array}$ & Localização & $\begin{array}{l}\text { Ano de } \\
\text { início }\end{array}$ & Objetivo \\
\hline $\begin{array}{l}\text { EUFOR* } \\
\text { ALTHEA }\end{array}$ & $\begin{array}{l}\text { Bósnia- } \\
\text { Herzegovina }\end{array}$ & 2004 & $\begin{array}{l}\text { Desenvolver as capacidades } \\
\text { das Forças Armadas do país. }\end{array}$ \\
\hline $\begin{array}{l}\text { EU NAVFOR*** } \\
\text { Somalia }\end{array}$ & Atalanta, Somália & 2008 & $\begin{array}{l}\text { Proteger embarcações } \\
\text { vulneráveis; interromper } \\
\text { ações de pirataria e roubo no } \\
\text { mar; monitorar atividades } \\
\text { de pesca na costa da Somália; } \\
\text { apoiar outras missões da UE } \\
\text { para fortalecer a segurança } \\
\text { marítima na região. }\end{array}$ \\
\hline $\begin{array}{l}\text { EUTM*** } \\
\text { Somalia }\end{array}$ & Somália & 2010 & Treinar soldados somalianos. \\
\hline $\begin{array}{l}\text { EU NAVFOR } \\
\text { Med } * * * *^{*}\end{array}$ & Mar Mediterrâneo & 2015 & $\begin{array}{l}\text { Interromper as rotas de } \\
\text { tráfico humano no } \\
\text { Mediterrâneo e evitar mais } \\
\text { mortes no mar. }\end{array}$ \\
\hline $\begin{array}{l}\text { EUTM } \\
\text { Mali****** }\end{array}$ & Mali & 2016 & $\begin{array}{l}\text { Fornecer treinamento às } \\
\text { Forças Armadas do Mali; } \\
\text { fomentar a manutenção do } \\
\text { respeito aos direitos humanos. }\end{array}$ \\
\hline $\begin{array}{l}\text { EUTM } \\
\text { RCA } * * * * * *^{*}{ }^{*} *{ }^{*}\end{array}$ & $\begin{array}{l}\text { República da África } \\
\text { Central }\end{array}$ & 2016 & $\begin{array}{l}\text { Apoiar as autoridades locais } \\
\text { na implementação da Reforma } \\
\text { do Setor de Segurança do país. } \\
\text { Construir capacidade e } \\
\text { qualidade. }\end{array}$ \\
\hline
\end{tabular}

*EUFOR: European Union Force; **EU NAVFOR: European Union Naval Force; ***EUTM: European Union Military Training Mission; ****EU NAVFOR Med: operation SOPHIA; ****** EUTM Mali (uma missão "não executiva” em que o efetivo empregado pela UE não participa de atividades de combate e não acompanha as unidades do Mali em operações); ********EUTM RCA (República Centro-Africana).

Fonte: SEAE 2018; 2016b. Elaboração: Henriques, Silva 2019. 
No caso do CDS, constam em seu estatuto de criação os objetivos gerais e específicos a serem perseguidos. Ao se ter em vista o funcionamento desse órgão no período no qual está situada esta investigação (2008-2016), aparecem algumas variações quanto à eficácia do Conselho, as quais podem ser atribuídas, principalmente, às mudanças políticas nos governos da região. Como exemplo, é possível observar que nos anos iniciais de seu funcionamento, momento em que os líderes políticos eram aqueles responsáveis pelo êxito da recém-criada UNASUL, era latente a preocupação de priorizar a construção das "bases institucionais, procedimentos e homogeneização de práticas e definições para criar o suporte de um sistema de cooperação, de coordenação e de confiança” (Teixeira Jr. 2015, 64). Na prática, tal preocupação resultou na consolidação de medidas de confiança mútua que objetivavam dirimir possíveis tensões na região, como, por exemplo, uma corrida armamentista.

As medidas de confiança mútua adotadas pelo CDS entre os anos de 2009 e 2012, dentre as quais é possível citar a criação do Centro de Estudos Estratégicos de Defesa, a promoção de seminários sobre questões ministeriais de defesa e, principalmente, a construção de uma metodologia comum para monitorar os gastos de defesa na América do Sul (Saint-Pierre e Palácios Junior 2014) assinalam a eficácia inicial do órgão. Ademais, a criação de grupos de trabalho específicos para realizar os objetivos definidos nos planos de ação e a constante publicização desses documentos também são fatores importantes. Resultados diretos dessas medidas iniciais puderam ser vistos na promoção dos Livros Brancos de Defesa dos Estadosmembros e na escolha de tornar transparente o sistema de divulgação de gastos em defesa (Saint-Pierre 2009).

Merece destaque também a criação de um documento específico que serviu como arcabouço institucional no processo de construção de confiança, intitulado Procedimientos de Aplicación para las Medidas de Fomento de la Confianza y Seguridad (2010), que reuniu diferentes áreas de abordagem para pensar o fomento da cooperação em segurança e defesa, que vão desde o intercâmbio de informações sobre Forças Armadas até assuntos referentes aos Ministérios da Defesa, passando também pelo desenvolvimento de regras para os gastos em defesa (Teixeira Jr. 2015). Logo, ao se considerar a importância dessas medidas para a robustez institucional pretendida com a criação do CDS, é possível inferir que em seus primeiros anos o órgão se mostrou eficaz e funcional, com governos comprometidos com o delineamento de uma agenda regional de segurança e defesa. Há que se considerar, contudo, que tais medidas ainda são limitadas para se pensar a cooperação regional na área da defesa, pois não vão além da construção de confiança, estando "ainda muito distantes de obedecerem a um 
desenho coerente com um processo cooperativo" (Saint-Pierre e Palácios Junior 2014, 35).

Por outro lado, entre os anos de 2014 e 2016, as mudanças políticas levadas a cabo nos países sul-americanos, principalmente ao se considerar os governos de Brasil e Argentina, em muito contribuíram para uma gradual desidratação e consequente diminuição da eficácia do CDS. É possível observar que a persecução dos objetivos regionais formais, na figura da agenda da Unasul/CDS, passou a destoar daqueles objetivos nacionais definidos pelos novos governantes, algo evidenciado na mudança de conteúdo dos planos de ação a partir de 2015 , cujas metas demonstram uma tendência à inércia do órgão, cada vez menos priorizado na agenda dos dois maiores países do subcontinente (Fuccille 2019). No caso argentino, a eleição de Mauricio Macri (2015-2019) significou um imediato distanciamento do processo cooperativo da Unasul, devido à forte oposição ideológica deste presidente para com os governos anteriores de Néstor e Cristina Kirchner (2003-2007 e 2007-2015, respectivamente), os quais participaram ativamente na gestação da instituição. Por conseguinte, a administração de Macri entendia haver um forte teor ideológico de inspiração bolivariana na cooperação, não condizente com as aspirações de cunho liberal propostas por seu governo, o que levou não apenas a uma perda de interesse pelo bloco, mas também a uma percepção de que a Unasul já não era mais útil aos governos da região.

Já no caso do Brasil, a manutenção do Partido dos Trabalhadores no poder com a eleição do primeiro mandato de Dilma Rousseff (2011-2014) significou a continuidade de muitas das medidas iniciadas no anterior governo de Lula da Silva (2003-2010), principalmente devido à prioridade conferida pela administração Rousseff ao setor da defesa, algo visto, por exemplo, com a publicação do Livro Branco de Defesa Nacional e com o incentivo industrial incorporado ao setor, que visava aproximar o desenvolvimento nacional e a defesa (Fuccille 2018). Entretanto, ainda neste governo, o CDS já era visto por grande parte dos altos oficiais militares como um projeto esquerdista (Fuccille 2019), sem razão de ser, e essa ideia ganhou reforço a partir de 2015, ao ser iniciado o processo de impeachment sofrido por Rousseff. Esse novo momento político, que levou à presidência o então vice-presidente Michel Temer (2016-2018), encontrou eco no posicionamento argentino, devido à postura de centro-direita e de caráter liberal proposta por Temer. Da mesma forma que Macri, a administração de Temer entendia que a Unasul e, consequentemente, o CDS, estavam impregnados de uma forte ideologia de esquerda, que já não era interessante para suas prioridades em termos de política externa.

Essa mudança no cenário político refletiu diretamente numa perda de eficácia do Conselho, que, a partir de 2015, tem seus Planos de Ação es- 
vaziados e generalizados, de maneira a tornar ardilosa a continuidade no aprofundamento da cooperação em defesa, outrora tida como prioridade no seio da Unasul. Ademais, ainda que o ano de 2017 não faça parte do recorte temporal pretendido neste trabalho, é mister perceber que a partir daquele ano a prática de lançar os planos de ação não tem sido realizada, o que reforça a percepção da perda de capacidade de ação do órgão."

\section{ASPECTOS INICIAIS}

Com o intuito de tornar mais factível a compreensão das categorias analíticas escolhidas como parâmetros de comparação neste trabalho, optou-se por uma divisão entre aspectos iniciais, institucionais e políticos. Neste sentido, por aspectos iniciais entende-se aquelas características intrínsecas aos órgãos estudados, as quais versam sobre sua história de formação. Escolheu-se a nomenclatura de aspectos iniciais devido à percepção de que tais atributos devem ser tomados como ponto de partida na comparação, pois são informações básicas e, ao mesmo tempo, fundamentais para a compreensão das diferenças existentes entre o Conselho de Defesa Sul-Americano e a Política Comum de Segurança e Defesa. Os aspectos iniciais de comparação aqui propostos são: natureza, origem e longevidade das instituições.

\section{Natureza}

A primeira diferença a ser destacada entre a PCSD e o CDS diz respeito à sua natureza, e corresponde a uma das políticas comunitárias da União Europeia, ou seja, um instrumento desenvolvido com a finalidade de auxiliar no cumprimento de objetivos a que se propõe a UE em uma determinada área. Apesar de esta política comunitária estar inserida no seio de um processo de integração de caráter supranacional, em lugar de estar restrita ao interior de uma máquina estatal, é possível utilizar-se o conceito de política pública para elucidar a natureza da PCSD, conforme proposto por Jobert e Muller (1987), segundo os quais trata-se de um esforço de coordenação de forças centrífugas. Logo, como parte do quadro de políticas comunitárias da União, a PCSD pode ser explicada como a política que estabelece o escopo de ação de suas estruturas civis e militares.

O Conselho de Defesa Sul-Americano, por sua vez, possui uma natureza mais fluida e menos rígida que a da PCSD, ao se constituir como um espaço de consulta, cooperação e coordenação em matéria de defesa, conforme enunciado no artigo primeiro de seu estatuto. É precisamente por esta razão que a capacidade decisória do órgão é menor frente à da política euro- 
peia, posto que a natureza de sua criação, que é um reflexo da natureza da própria Unasul, possui uma finalidade de concertação entre as diferentes percepções políticas que a compõem. Diferente do que ocorre com a PCSD, que estabelece um quadro de ação para os membros da União, o CDS ainda busca a formação de consensos e a construção de um pensamento sul-americano em defesa, algo, todavia, embrionário na história da cooperação regional da América do Sul nesse setor.

\section{Origem}

Um segundo ponto crucial nas diferenças observadas entre a PCSD e o CDS reside em suas origens. A política europeia é a "cereja do bolo" de um extenso histórico de tentativas de se chegar a uma defesa comum no interior do bloco, algo vislumbrado ao longo dos mais de 50 anos do processo de integração iniciado ainda nas Comunidades Europeias. Os ímpetos europeus de superar o tabu em temas de defesa, resultante das duas grandes guerras das quais a Europa foi palco e que teve como atores principais Estados europeus, passaram pelas frustradas iniciativas da Comunidade Europeia de Defesa e da União da Europa Ocidental, até que fosse possível definir uma Política Externa e de Segurança Comum (PESC), em 1992, com o Tratado de Maastricht. Assim, a PESC representa o embrião do intuito da UE em construir uma identidade de defesa com suas características próprias, e seus resultados têm sido palpáveis, na medida em que acompanham o aprofundamento da integração via renovação e reformulação de tratados.

Contudo, antes de se chegar aos moldes da atual PCSD, é preciso relembrar sua antecessora, a Política Europeia de Segurança e Defesa (PESD), que, a partir do Tratado de Nice (2001), lançou as bases para a estrutura de ação externa da União, por meio, principalmente, das Missões de Petersberg. Assim, em 2009, a PESD é oficialmente encerrada e substituída pela PCSD, que passa a ser o atual estágio da cooperação em segurança e defesa no interior da UE, de forma a conferir maior robustez à gradual persecução da identidade de defesa europeia. Portanto, longe de ser um processo recente, a PCSD se apresenta como a resultante de um acúmulo de tentativas para garantir que a inquestionável força política do bloco europeu possa chegar a ser também inquestionável do ponto de vista do hard power.

Num contexto diametralmente oposto ao da PCSD, o CDS representa o primeiro avanço factível em termos de possibilidades de cooperação em defesa no subcontinente americano, ao reunir todos os países que compõem geograficamente a região - algo explicitado em seu nome - e excluir a presença de centro e norte-americanos, inclusive os EUA. É fato que o su- 
cesso na formulação de tal iniciativa encontrou respaldo na onda de governos considerados progressistas, ou mais à esquerda no espectro político, pela qual passou a América do Sul durante os anos 2000, além dos resultados positivos oriundos do boom exportador de commodities experimentado pela região (Sanahuja 2016); contudo, é pertinente considerar ainda dois fatores-chave na propulsão do órgão:

Dois acontecimentos regionais incidiram fortemente na criação e consolidação do CDS: o bombardeio colombiano em Angostura, Equador, em 2008 e os acordos sobre as bases militares ColômbiaEUA (Palacios 2011a, 2011b). Esses eventos permitem vislumbrar a própria gênese do CDS como a institucionalização da expressão política de uma vontade regional que se propõe a resolver os conflitos sul-americanos autonomamente, sem ingerência de atores extrarregionais e que, uma vez criado, poderia desenvolver e aprimorar instrumentos e métodos específicos de confiança para os âmbitos estratégico e tático (Donadio 2010) (Saint-Pierre and Palacios Junior 2014, 29).

Por este ângulo, é possível depreender a construção do Conselho como um divisor de águas na história da cooperação em defesa sul-americana, ainda que sejam consideradas suas limitações e entraves, posto que a vontade dos países em dar continuidade à aproximação nesse setor é algo sem precedentes. Soma-se a isso o fato da não participação estadunidense, o que, mesmo levando-se em conta o fato de que os EUA tenham sido consultados sobre os moldes nos quais deveria ser estruturado o CDS para não ferir sua hegemonia na região, significa uma maior autonomia na concertação de interesses exclusivamente sul-americanos. Uma última questão a ser observada quanto às origens do Conselho diz respeito à evolução positiva na construção de confiança entre vizinhos geograficamente próximos, mas que cultivavam antecedentes de distanciamento e desgaste resultantes de históricos entraves territoriais que culminaram em conflitos bélicos nos séculos XIX e XX e cujas consequências se fizeram sentir por meio do receio na aproximação em temas de defesa. Destarte, as instituições aqui tratadas partem de origens completamente distintas, mas, em alguma medida, encontram na finalidade da gradual construção de uma identidade de defesa um ponto em comum.

\section{Longevidade}

A despeito de suas particularidades quanto às origens, a PCSD e o CDS possuem um período de existência relativamente semelhante. A primeira data do ano de 2009, a partir da entrada em vigor do Tratado de Lisboa, que veio reformular a estrutura e o funcionamento da União Europeia, ao mesmo tem- 
po em que extinguiu a PESD e criou a PCSD. A política encontra-se em pleno vigor até o ano atual (2020), apesar de aqui a análise de seu funcionamento chegar apenas até o ano de 2016. Devido ao histórico europeu de substituição de políticas por meio da reformulação e assinatura de novos tratados, é possível conjecturar que, caso a finalidade da construção da identidade de defesa europeia continue como uma das prioridades da UE, em algum momento a PCSD será sucedida por uma política ainda mais robusta, que seja capaz de reparar as falhas e limitações deixadas pelo atual desenho político de defesa.

Por seu turno, o CDS foi oficialmente criado no ano de 2008, alguns meses após a criação da Unasul, por meio do Estatuto do Conselho de Defesa Sul-Americano. Seu funcionamento efetivo pode ser visto até o ano de 2017, quando foi lançado o último plano de ação de que se tem registro. Como consequência do desmonte da Unasul, observado nos meses iniciais de 2019 quando do anúncio de retirada do fórum por parte de Argentina, Brasil, Chile, Colômbia, Equador, Paraguai e Peru, o CDS encontra-se em um estado de latência e estagnação. $O$ cenário político da região aponta para a substituição da Unasul pelo Prosul, um novo bloco que se pretende desprovido de ideologias de esquerda e alinhado aos interesses neoliberais dos novos governantes que assumiram o poder nos países da região a partir de 2018, o que, consequentemente, retira o sentido do CDS de agregar todos os Estados sul-americanos em um espaço para pensar de forma conjunta as questões de defesa.

\section{ASPECTOS INSTITUCIONAIS}

A segunda divisão proposta para um melhor entendimento a respeito das categorias analíticas utilizadas aqui para a comparação diz respeito aos aspectos institucionais da Política Comum de Segurança e Defesa e do Conselho de Defesa Sul-Americano. Passado o primeiro momento de compreensão a respeito da história e formação de ambas as instituições, cabe compreender agora de que forma o desenho institucional torna-se relevante para se pensar a inconstância das variáveis que atuam sob o processo de aprofundamento da cooperação em segurança e defesa. As categorias entendidas como aspectos institucionais são: modelo institucional, estrutura, regra decisória e amplitude da agenda e dos objetivos.

\section{Modelo institucional}

No tradicional estudo dos desenhos institucionais de organismos internacionais, a literatura tende a ser dividida entre as vertentes supranacional e intergovernamental, em que a primeira, via de regra, é mais 
cara aos estudiosos institucionalistas, ao passo que a segunda tende a ser mais investigada pelos realistas. Consequentemente, ao se destrinchar as características de determinada instituição, outra tendência verificada é a de definir se esta é intergovernamental ou supranacional, conforme a preponderância de elementos de uma ou outra vertente. Contudo, segundo o pensamento de Pereira (2012), que retoma autores como Sweet e Sandholtz (1997), é possível depreender que a rígida definição de um organismo como intergovernamental ou supranacional não é interessante, pois o que geralmente ocorre é a mescla de elementos das duas vertentes em um mesmo organismo. Neste sentido, o que se tem é um espectro em que um dos polos seria o modelo intergovernamental e o outro o modelo supranacional, no qual as instituições vão transitar, ora mais próximas a uma extremidade, ora mais fluidas e situadas ao centro ou à outra extremidade, permitindo a concepção de um caráter híbrido em muitas situações.

Isso posto, na tentativa de situar as instituições aqui analisadas em algum lugar do espectro dos desenhos institucionais, considera-se que a PCSD está inserida num contexto que se aproxima mais do extremo da supranacionalidade no seio da União Europeia, ainda que conte com importantes atributos do intergovernamentalismo, enquanto o CDS está mais próximo do polo intergovernamental, que é predominante na Unasul, com poucas atribuições de caráter supranacional.

De maneira a situar conceitualmente os termos empregados na definição de cada instituição, para que seja possível perceber a diferença que reside entre elas, é utilizada a definição proposta por Joana Stelzer (2001, 69) a respeito do que se configura como supranacionalidade:

[...] expressa um poder de mando superior aos Estados, resultado da transferência de soberania operada pelas unidades estatais em benefício da organização comunitária, permitindo-lhe a orientação e a regulação de certas matérias, sempre tendo em vista os anseios integracionistas.

De igual modo, a definição de intergovernamentalismo, trazida por Malamud (2005, 139), é empregada como ponto de partida para pensar esse modelo institucional. Nas palavras do autor:

Liberal intergovernmentalism sees economic interdependence as a strong pre-condition for integration. As trade liberalization augments export dependence and intra-industry trade, stronger pressure for integration arises. Regional institutions are thus conceived of as mechanisms to lock in and enforce agreements rather than as autonomous actors or broader political arenas. In spite of the crucial weight this approach accords national states, the decision to either pool or delegate power to the regional level is regarded as unavoidable to allow for higher levels of complex interaction. 
A partir destes conceitos-chave, é possível inferir que, no caso da PCSD, o forte teor supranacional percebido no processo de integração atinge com maior força o setor econômico do bloco, haja vista a necessidade de que haja uma transferência de soberania por parte das unidades estatais para as esferas comunitárias. Entretanto, deve-se considerar que, em termos da política de segurança e defesa, o aspecto intergovernamental apresenta-se mais relevante que o supranacional, conforme explicitado no próprio Tratado de Lisboa $\left(\mathrm{n}^{\circ} 2\right.$, art. $42^{\circ}$ do TUE), onde se lê que “a política da União [...] não afetará o caráter específico da política de segurança e defesa de determinados Estados-membros”. Portanto, o fato de tal política não interferir diretamente numa transferência de competência para a União, por respeitar a autonomia estatal, leva ao entendimento de que esta encontra-se mais próxima do polo intergovernamental no espectro dos desenhos institucionais, o que reforça a argumentação de Sweet e Sandholtz (1997), segundo a qual a rigidez na definição do modelo institucional não é a melhor forma de se analisar organismos internacionais.

Por outro lado, ao se observar as características da Unasul desde sua criação, com foco na concertação política regional sul-americana, nota-se que os atributos intergovernamentais são evidenciados em todos os aspectos do processo, algo que tem sido uma regra em todas as tentativas de cooperação multilateral na região (Malamud 2005). Assim, a influência presidencial percebida no foro multilateral em questão atinge também o Conselho, que, apesar de buscar a construção de uma identidade de defesa para a América do Sul, está longe de interferir diretamente na autonomia dos Estados-membros no que diz respeito às suas políticas de defesa. Como mencionado em seu estatuto de criação, a prioridade é que o espaço se constitua como passível de coordenar as diferentes políticas de defesa já existentes, de maneira a proporcionar uma aproximação nesse setor, tão marcado por distanciamentos e desconfianças.

Assim, através da análise das características dos modelos institucionais nos quais estão inseridas a PCSD e o CDS, é plausível a inferência de que há um ponto em comum entre ambas, já que, apesar da predominância supranacional no processo de integração europeu, quando o assunto é a defesa comum, as dificuldades em transferir totalmente a autonomia para o nível comunitário são preponderantes. É verdade que grande parte dessa dificuldade está diretamente relacionada à importância que o setor da defesa guarda no que diz respeito à soberania estatal, o que auxilia no entendimento do motivo de a UE ainda apresentar marcas fortes de intergovernamentalismo mesmo ao contar com uma robustez institucional no nível comunitário. 


\section{Estrutura}

O seguinte elemento de análise aqui proposto é a estrutura organizacional da PCSD e do CDS, fundamental para se compreender quão densas são as composições de cada instituição. O intuito desta categoria analítica é elucidar como as diferentes possibilidades de estrutura em organismos internacionais podem interferir em seu funcionamento.

No caso da PCSD, sua condução, execução e definição estão sob responsabilidade da Alta Representante da União para os Negócios Estrangeiros e a Política de Segurança, cargo ocupado por Federica Mogherini entre os anos de 2014 e 2019. A nomeação do mencionado cargo é deliberada via maioria qualificada no âmbito do Conselho Europeu, que tem a prerrogativa também de finalizar o mandato pelo mesmo procedimento $\left(\mathrm{n}^{\circ} 1\right.$, art. $18^{\circ}$ do TUE). Ainda, a Alta Representante consulta regularmente o Parlamento Europeu sobre possibilidades a respeito da PCSD, de forma a garantir que esta instituição tenha sua voz ouvida na condução da política. Em referência à característica intergovernamental da PCSD, mencionada na seção anterior deste texto, está a participação ativa dos Estados-membros, que colocam suas capacidades civis e militares à disposição da União de forma a tornar possível a execução desta política. Por fim, o encargo operacional da PCSD fica sob a tutela da Agência Europeia de Defesa, que:

[...] identifica as necessidades operacionais, promove as medidas necessárias para as satisfazer, contribui para identificar e, se necessário, executar todas as medidas úteis para reforçar a base industrial e tecnológica do sector da defesa, participa na definição de uma política europeia de capacidades e de armamento e presta assistência ao Conselho na avaliação do melhoramento das capacidades militares $\left(\mathrm{n}^{\circ}\right.$ 3 , art. $42^{\circ}$ do TUE).

No que se refere ao CDS, os artigos 6, 7, 8, 9 e 10 de seu Estatuto definem a conformação de sua estrutura de funcionamento. Por estes artigos, fica estabelecido que a presidência do CDS será a mesma que a presidência Pro Tempore da Unasul, cuja função é coordenar as atividades do organismo. O Conselho está integrado também pelas ministras e ministros de Defesa, ou seus equivalentes, dos países-membros, por delegações nacionais, compostas pelos Altos Representantes de Relações Exteriores e Defesa, bem como por seus assessores, estes últimos apenas no caso de os Estados considerarem relevante sua participação. Há ainda uma instância executiva, formada pelas vice-ministras e vice-ministros de Defesa, ou seus equivalentes e, por fim, existe a prerrogativa da formação de grupos de trabalho para o exame de assuntos específicos, que podem servir para 
recomendar ou sugerir questões de ordem variada. A periodicidade das reuniões ordinárias do Conselho é anual (Unasul 2008, art. 12º ), porém há sessões a cada seis meses da instância executiva (Unasul 2008, art. $14^{\circ}$ ), além de existir a possibilidade de reuniões extraordinárias sob a petição de metade dos Estados-membros (Unasul 2008, art. 15 ${ }^{\circ}$ ).

Logo, observa-se que, ainda que com fortes traços intergovernamentais, ambos os organismos aqui analisados são estruturalmente distintos, o que não tem sido determinante na eficácia de seu funcionamento e, por esta razão, pode-se considerar que os aspectos institucionais podem não ser o fator de maior peso para o cumprimento dos objetivos propostos, embora sejam relevantes para o entendimento da PCSD e do CDS.

\section{Regra decisória}

A maneira como ocorre o processo de tomada de decisão no seio de uma instituição de cunho internacional é outro aspecto variável e que, sistematicamente, deve ser levado em consideração ao se buscar compreender esses organismos. No caso da UE, por se tratar de um processo de integração no qual a supranacionalidade é latente, grande parte das decisões são tomadas pelas instituições europeias em um burocrático procedimento que envolve desde o Parlamento Europeu até o Conselho, passando também pela Comissão. Contudo, o caráter intergovernamental e sensível das decisões que dizem respeito às questões de segurança e defesa — que é o caso da Política Comum de Segurança e Defesa - não atingiu a transferência de autonomia para as mencionadas instituições comunitárias.

É por esta razão que as propostas com relação à PCSD - como, por exemplo, propostas de lançamento de missões — são feitas pela Alta Representante, ou por algum dos Estados-membros, sendo deliberadas no âmbito do Conselho Europeu, composto pelos dirigentes dos Estadosmembros, e requerem unanimidade para que sejam adotadas. Cabe ainda à Alta Representante a prerrogativa de propor o emprego de recursos nacionais ou da UE, algo que pode ser realizado juntamente com a Comissão (n ${ }^{\circ} 4$, art. $42^{\circ}$ do TUE).

Por outro ângulo, inserido no contexto de coordenação política da Unasul, o Conselho de Defesa Sul-Americano também tem suas decisões deliberadas via unanimidade. O artigo 13 do Estatuto do CDS faz referência direta ao $12^{\circ}$ artigo do Tratado Constitutivo da Unasul para explicar sua forma de proceder em termos de tomada de decisão; segundo este artigo, os pareceres por consenso poderão ser adotados desde que estejam presentes no mínimo três quartos dos Estados-membros e, no caso de deliberações com Estados ausentes, a regra é que estes sejam consulta- 
dos por meio do Secretário Geral, obedecendo a um prazo de até 30 dias corridos para se manifestarem, salvo no caso do Conselho de Delegadas e Delegados, que conta com um prazo de apenas 15 dias. Além disso, os grupos de trabalho, quando os houver, têm a prerrogativa de realizar sessões e apresentar propostas sempre que as reuniões apresentem um quórum de metade mais um dos Estados-membros.

Diante do exposto, verifica-se um ponto de encontro entre a PCSD e o CDS, e isso faz com que se retome a ideia de que as instituições transitam no espectro dos modelos institucionais, devido a esta característica similar. Sugere, ainda, que o desenho institucional não é o fator determinante para se pensar a eficácia e o pleno funcionamento das instituições, reforçando o argumento de que a variável determinante para se compreender a cooperação em segurança e defesa, variável esta a independente deste estudo, implica aspectos de caráter político.

\section{Amplitude da agenda e dos objetivos}

$\mathrm{O}$ último aspecto de cunho institucional analisado aqui, e nem por isso menos importante, diz respeito às agendas e objetivos da PCSD e do CDS. O que se pretende nesta categoria de análise é verificar a abrangência das agendas destas instituições, para que se possa aferir o comprometimento dos Estados-membros com o projeto em comum suscitado por cada uma delas. Neste sentido, chama a atenção um aspecto encontrado nos documentos-base de ambas as organizações e que faz referência à persecução de uma identidade de defesa europeia e sul-americana, respectivamente. A relevância deste ponto é crucial, pois demonstra a intencionalidade dos Estados-membros de construir, gradualmente, algo mais forte do que apenas uma percepção partilhada do que deve ser a defesa no âmbito regional. A presença do conceito de identidade confere maior profundidade a ambos os processos, pois o fato desta palavra aparecer na lógica discursiva das instituições através de seus textos fundamentais denota um comprometimento para com a ordem regional em segurança e defesa, devido ao peso do discurso dos atores para as construções sociais de significado (Onuf 1989).

Por outro lado, para além das questões identitárias subjetivas, em termos práticos as diferenças nas agendas aqui analisadas são marcantes. Do ponto de vista da política europeia, é possível afirmar a existência de uma maior amplitude da agenda, o que pode ser visualizado, por exemplo, na possibilidade da realização de missões conjuntas entre os Estadosmembros, ou, ainda, na prerrogativa do estabelecimento de uma defesa comum, quando assim o decidir o Conselho Europeu $\left(\mathrm{n}^{\circ} 2\right.$, art. $42^{\circ}$ do 
TUE). Além disso, o fato de tal política estar em consonância com a já estabelecida Organização do Tratado do Atlântico Norte (OTAN) lhe confere maiores possibilidades em seu escopo de atuação. Em contrapartida, o exame do Tratado de Lisboa (2009) e da Estratégia Global para a política externa e de segurança da UE (2016) revela uma ausência de objetivos claramente delineados no que diz respeito às ações da PCSD. Ambos os documentos são generalizantes em termos do que se espera da política europeia, mas não são precisos em delimitar objetivos a serem perseguidos, o que é um problema mais grave do ponto de vista da Estratégia Global, considerando-se que a função de uma estratégia é justamente definir quais serão e como serão alcançados os objetivos em questão, como bem resume Esther Barbé $(2016,3)$ : "el término de pensamiento estratégico nos remite a establecer la manera de utilizar los medios o recursos disponibles para obtener los objetivos propuestos".

Depreende-se então que a falta de definições precisas quanto aos objetivos da PCSD é mais um sintoma da dificuldade da União em se colocar como um ator estratégico diante do cenário das Relações Internacionais. Ao contrário disto, o comportamento observado, principalmente nas áreas de defesa e segurança, tem sido reativo e normativo: reativo, pois há uma falta de planejamento, posto que as ações são tomadas a partir do fluxo com que se dão os acontecimentos, numa lógica imediatista de reação; e normativo, pois suas ações visam exportar o modelo europeu de valores, algo que se opõe à racionalidade tradicional dos atores internacionais, que atuam com base em seus interesses materiais (Barbé 2016). Já no Tratado de Lisboa, o artigo $45^{\circ}$ é o que mais se aproxima da definição de objetivos específicos, ao estipular a missão da Agência Europeia de Defesa, responsável pelo desenvolvimento das capacidades de defesa da UE.

No que diz respeito ao CDS, há uma amplitude menor na definição da agenda e dos objetivos, como se pode ver, por exemplo, pela tentativa de gerar consensos para fortalecer a cooperação regional em defesa e pela adoção de medidas de fomento da confiança. Contudo, a despeito da variação na amplitude da agenda ser menos perceptível, deve-se notar que há uma maior precisão quanto aos objetivos que se pretende alcançar, o que poderia resultar em um órgão mais eficaz do ponto de vista da entrega de resultados, não fosse a predominância dos aspectos políticos.

Neste sentido, o Estatuto de criação do Conselho, em sua terceira seção, delimita explicitamente os objetivos gerais (Unasul 2008, art. $4^{\circ}$ ), que são três, e os objetivos específicos (Unasul 2008, art. $5^{\circ}$ ), que são onze, o que demonstra um entendimento inequívoco sobre onde se pretende chegar com a cooperação regional em defesa. $\mathrm{Na}$ análise dos objetivos específicos, a pequena amplitude, bem como o caráter consultivo do órgão, ficam 
evidentes na escolha das palavras que compõem o texto, principalmente através do significado dos verbos que iniciam cada objetivo e das repetições em seu uso. Os verbos empregados são: avançar, promover, contribuir, fortalecer, fomentar, compartilhar e trocar, denotando a consonância entre a natureza da coordenação de diferentes visões do CDS e a busca, a longo prazo, da identidade de defesa sul-americana. Observa-se também nos planos de ação do Conselho (que refletem sua agenda anual) a divisão de temáticas por eixos, bem como o rígido cronograma para o cumprimento de tarefas e a determinação de responsáveis para cada ação, o que demonstra a racionalidade que permeia a busca da execução dos objetivos. Trata-se, portanto, de um órgão com menor capacidade de agência, mas que possui uma intencionalidade mais bem desenhada, fazendo com que sua possibilidade de eficácia seja otimizada.

\section{ASPECTOS POLÍTICOS}

O último elemento analítico proposto para a comparação das unidades aqui estudadas muda o foco da análise para a relevância das questões políticas. Depois de verificadas as diferenças marcantes quanto aos aspectos básicos e institucionais, o objetivo é aferir se, de fato, a variável determinante para o não aprofundamento da cooperação em segurança e defesa tem suas raízes nos atributos políticos da regionalização. Com este fim, há que se retomar a teorização de Buzan e Waever (2003) a respeito dos Complexos Regionais de Segurança, de forma a situar os níveis desta análise. Dos quatro níveis propostos pelos autores, apenas dois interessam para este estudo, quais sejam, o nível doméstico de cada Estado na região e o nível das relações entre Estados de uma mesma região, isto é, a questão política que interfere no âmbito institucional está situada no intermédio entre os interesses e vulnerabilidades de cada Estado e nas interações que ocorrem no sentido intrarregional. Logo, torna-se possível afirmar que, em ambos os níveis, os fatores de ordem política ocupam lugar de destaque, considerando-se os descompassos que permeiam o espectro político.

Por conseguinte, deve-se compreender que nem todos os Estados de uma região têm o mesmo peso político no esquema decisório que define o aprofundamento ou não da cooperação, que, neste caso, diz respeito à área da segurança e defesa; é então necessário que se desenvolva uma outra conceituação para tratar daqueles Estados que detêm o poder de decisão, as chamadas potências regionais. Contudo, tal conceituação não é tão simples de ser desenvolvida, já que o mencionado status não está relacionado apenas aos recursos de poder de que dispõe um determinado Estado, seja em termos de soft power, hard power ou smart power, ${ }^{5}$ mas também "with per- 
ceptions about the configuration of global and regional power hierarchies. It also has to do with the role definitions of political elites regarding a country's position within such power hierarchies" (Nolte 2010, 892).

Logo, ainda na linha de raciocínio de Buzan e Waever (2003), potências regionais são explicadas como aqueles atores capazes de definir a polaridade de um complexo regional de segurança, cujas capacidades em termos de poder são consideráveis, mas estão restritas ao contexto regional. Esta definição por si só é válida para o que se busca neste estudo; no entanto, Nolte (2010, 890) também aporta uma caracterização interessante conceitualmente ao diferenciar potências médias de potências regionais: de acordo com o autor, estas últimas geralmente combinam atributos de liderança e recursos de poder, além de acumular uma responsabilidade especial no que diz respeito à segurança e à manutenção da ordem regionais. Nolte considera ainda três outros pontos cruciais, propostos por Schoeman (2003, 353), como condições para o status de potência regional:

The internal dynamics of such a state should allow it to play a stabilizing and leading role in its region; Such a state "should indicate and demonstrate its willingness, and of course also its capacity or ability, to assume the role of regional leader, stabilizer and, if not peacekeeper, or at least peacemaker"; "Should be acceptable to its neighbours — the members of the security complex in which it operates - as a leader responsible for regional security. A broader, or extra-regional acceptance is perhaps a necessary condition, but not sufficient, even if supported and promoted by big powers".

Neste ínterim, é importante considerar que a caracterização de uma potência regional faz referência direta à influência exercida em uma determinada região geográfica e pode variar a depender do assunto analisado, não sendo, portanto, uma atribuição imutável. Ainda, o mesmo Estado caracterizado como potência regional pode ter um status de potência média ou grande potência numa escala global, o que demonstra que o conceito de potência regional está intrinsecamente conectado com a lógica hierárquica da região em questão (Nolte 2010). A partir desta situação teórica, é possível avançar com a análise comparada sobre os aspectos políticos que permeiam a cooperação em segurança e defesa nas instituições aqui estudadas.

\section{Nível de convergência das potências regionais}

A conjectura política que possibilitou o surgimento da Política Comum de Segurança e Defesa a partir de 2009, com a assinatura do Tratado de Lisboa, está assentada no ano de 1998, na declaração de Saint-Malo. Tal declaração demonstra que a convergência dos interesses políticos das potências regionais é imprescindível para o avanço da cooperação em se- 
gurança e defesa, tendo sido responsável pela aproximação política entre França e Reino Unido, potências regionais que desde o início do processo de integração divergiam sobre os rumos da defesa europeia. Enquanto a França historicamente buscava desenvolver um pilar europeu em termos de defesa, desatrelado dos interesses estadunidenses e de maneira a garantir autonomia, o Reino Unido sustentava a postura de manter a segurança europeia sob a tutela dos EUA, principalmente na figura da OTAN, inviabilizando, assim, qualquer tentativa de levar adiante o debate sobre segurança e defesa no interior das comunidades europeias.

A partir de 1997, contudo, a mudança política que se deu na liderança do Reino Unido com a eleição de Tony Blair pelo partido Trabalhista, somada à relutância por parte do governo estadunidense de Bill Clinton (1993-2001) em levar adiante os custos da segurança europeia, vieram a mudar o panorama. Longe de buscar um afastamento da OTAN na gestão da segurança europeia, o Reino Unido percebeu que a melhor maneira de manter o envolvimento dos EUA nessas questões tão sensíveis seria por meio da adoção pragmática de meios independentes no âmbito da defesa da UE, de forma a reduzir os custos para os estadunidenses. Assim, com o intuito de reforçar seu interesse na relação transatlântica, Londres optou por aceitar a ideia de criar capacidades autônomas de ação para a União nos quadros da segurança e defesa, algo que rompeu um tabu instaurado no seio da UE desde a entrada do Reino Unido nesta, em 1973 (FerreiraPereira 2005).

Esta mudança de posicionamento político resultou em uma aproximação em relação aos interesses franceses, que não encontravam eco justamente pela oposição britânica, e permitiu que fossem lançadas as bases para a criação da PESD, que mais tarde viria a se tornar a PCSD. Aqui cabe reafirmar que a intenção em manter latente a conexão com os EUA foi evidenciada na declaração de Saint-Malo, que explicitava o interesse europeu em cooperar com o quadro da já estabelecida aliança militar, num formato em que a segurança e defesa europeias estivessem a serviço da OTAN. Portanto, ainda que as capacidades a serem desenvolvidas no âmbito da União fossem inteiramente alinhadas com os desígnios da Aliança, foi consolidada uma aproximação política tida quase como impossível entre França e Reino Unido (Ferreira-Pereira 2005), da qual dependeu o sucesso de uma política comum no quadro da defesa europeia, o que reforça o argumento de que a convergência entre as potências regionais é basilar para que seja possível conceber a cooperação em segurança e defesa no nível regional.

Neste sentido, a reformulação da PESD, que delineou a PCSD em 2009, demonstra a predominância do aspecto político no que diz respeito à construção europeia em segurança e defesa, já que a nova política permanece 
num quadro de linha auxiliar da OTAN $\left(\mathrm{n}^{\circ} 2\right.$, art. $42^{\circ}$ do TUE), de forma a não ferir a relação transatlântica entre a Europa e os EUA.

De igual modo, ao se observar o cenário político que possibilitou a conformação do Conselho de Defesa Sul-Americano, no âmbito da criação da Unasul, é possível verificar a existência de dois projetos políticos concorrentes entre Brasil e Venezuela. Por um lado estava a Venezuela chavista, com um projeto de defesa comum intenso, que visava sobretudo a unificação das Forças Armadas da região sul-americana, numa tentativa direta de se contrapor à unipolaridade estadunidense. Tal projeto, patrocinado pelo governo de Hugo Chávez (1999-2013), entendia que a principal ameaça à segurança mundial eram os EUA e, portanto, buscava uma união entre os Estados da América Latina como forma de estabelecer um polo de poder capaz de limitar os ímpetos estadunidenses. Para tanto, a proposta era de que a criação do conselho de defesa lançasse as bases para o surgimento de uma instituição de caráter majoritariamente militar, que seria a Organização do Tratado do Atlântico Sul (OTAS), numa clara referência de oposição à OTAN.

Este projeto, entretanto, não encontrou respaldo na maioria dos governos da região, salvo na Bolívia, Equador e Argentina, o que não foi suficiente para permitir seu avanço. Ademais, o histórico recente de ditaduras militares no subcontinente resultou num receio em participar de uma organização de caráter eminentemente militar, algo que contribuiu para que o projeto não passasse de uma idealização.

De outro lado do espectro político, com um caráter mais conciliatório, o projeto brasileiro - que veio a se tornar de fato o Conselho de Defesa SulAmericano - conseguiu fazer convergir os interesses políticos de todos os países da região. O intuito do Brasil em se estabelecer como líder regional sul-americano tinha a finalidade máxima de conquistar um assento no Conselho de Segurança da ONU, daí a proposta de criação de um órgão de aspecto mais brando, que contribuísse para a mudança da percepção dos demais Estados sul-americanos de que Brasília possuía ímpetos imperialistas na região, para que fizessem coro ao projeto. A possibilidade de contar com a participação da Colômbia, por exemplo, país historicamente alinhado aos EUA, mesmo após alguns anos de negociação, demonstra o alto nível da concertação política que se deu na consecução do CDS.

Outro fator relevante a se considerar na criação do CDS foi que este contou com o aval dos EUA, posto que a natureza consultiva do órgão, somada à sua baixa capacidade de agência, não implicava em uma aliança militar para a região (Diamint 2013), o que não diminui o prestígio de um organismo idealizado para pensar a defesa exclusivamente sul-americana e sem a participação de Washington. Outrossim, o projeto conseguiu conci- 
liar as intenções brasileiras com posicionamentos divergentes, como aqueles de Venezuela e Colômbia, e sua criação denota a convergência política que se deu entre a potência regional, no caso o Brasil, e aqueles países que, apesar de não se constituírem enquanto potências regionais, teriam força para barrar a consolidação do Conselho. A Colômbia, por exemplo, era contrária à proposta do CDS por acreditar que este seria uma redundância ao trabalho já desenvolvido pela OEA, além de considerar insuficiente o esforço de cooperação regional no combate às FARC (Abdul-Hak 2013).

Por esta perspectiva, o caso do CDS permite uma melhor visualização da predominância dos aspectos políticos no que diz respeito ao aprofundamento da cooperação regional em segurança e defesa, já que sua existência foi possível, em grande medida, pela convergência política ocorrida entre os países sul-americanos nos anos 2000, quando houve uma maioria de governos de caráter mais progressista ou de centro-esquerda, cujos projetos regionais apontavam para uma maior aproximação no eixo sul-americano. Tal convergência política, contudo, foi rompida a partir de 2016, quando há uma mudança nas características dos novos governantes que passam a assumir o poder na região. Estes, mais alinhados com projetos neoliberais e de centro-direita, demonstraram perda de interesse na continuidade da Unasul e, consequentemente, na manutenção do Conselho.

\section{CONSIDERAÇÕES FINAIS}

Por fim, após análise individual de cada uma das categorias em que a comparação foi baseada, as informações obtidas foram sistematizadas em formato de quadro (Quadro 2), de modo a situar as unidades com relação aos atributos observados e apresentar de maneira objetiva o resultado da análise comparada desenvolvida ao longo deste texto.

Como se pode observar no quadro comparativo, as categorias analíticas serviram como indicadores das diferenças marcantes entre a PCSD e o CDS, ao evidenciar como os dois organismos representam formas diferentes de buscar a cooperação em segurança e defesa no nível regional. Em termos de estratégia de pesquisa, a comparação sistematizada oferece um panorama que identifica quais são as variáveis determinantes que atuam sobre a variável dependente, de maneira a tornar mais perceptível a interação entre elas. Neste caso, o que se verificou foi uma influência preponderante da incidência dos aspectos políticos em detrimento daqueles iniciais e institucionais, tendo como resultado momentos alternados entre maior e menor vontade política para aprofundar a cooperação. 


\section{Quadro 2}

Aspectos de comparação entre a PCSD e o CDS

\begin{tabular}{|c|c|c|}
\hline & $\begin{array}{c}\text { Política Comum de Segurança } \\
\text { e Defesa }\end{array}$ & $\begin{array}{l}\text { Conselho de Defesa } \\
\text { Sul-Americano }\end{array}$ \\
\hline Natureza & $\begin{array}{l}\text { A PCSD é a política que } \\
\text { estabelece o quadro para as } \\
\text { estruturas políticas e militares da } \\
\text { União Europeia. }\end{array}$ & $\begin{array}{l}\text { O CDS é uma instância } \\
\text { de consulta, cooperação e } \\
\text { coordenação em matéria de defesa } \\
\text { na Unasul. }\end{array}$ \\
\hline Origem & $\begin{array}{l}\text { É a atual resultante das tentativas } \\
\text { de cooperação em segurança e } \\
\text { defesa no seio da UE, que vêm } \\
\text { desde o estabelecimento da } \\
\text { Política Externa e de Segurança } \\
\text { Comum (PESC) e passa pela } \\
\text { anterior Política Europeia de } \\
\text { Segurança e Defesa (PESD). }\end{array}$ & $\begin{array}{l}\text { É a primeira iniciativa de } \\
\text { cooperação em defesa que está } \\
\text { restrita e composta apenas por } \\
\text { Estados sul-americanos. }\end{array}$ \\
\hline Longevidade & $\begin{array}{l}\text { Estabelecida em } 2009 \text { no Tratado } \\
\text { de Lisboa e ainda em vigor } \\
(2019) .\end{array}$ & $\begin{array}{l}\text { Criado em } 2008 \text { por meio } \\
\text { do Estatuto do Conselho de } \\
\text { Defesa Sul-Americano e com } \\
\text { funcionamento pleno até o ano } \\
\text { de } 2017 .\end{array}$ \\
\hline $\begin{array}{l}\text { Modelo } \\
\text { institucional }\end{array}$ & $\begin{array}{l}\text { Supranacional/ } \\
\text { intergovernamental }\end{array}$ & Intergovernamental \\
\hline Estrutura & $\begin{array}{l}\text { Conselho Europeu; Alto } \\
\text { Representante da União para } \\
\text { os Negócios Estrangeiros e a } \\
\text { Política de Segurança; Parlamento } \\
\text { Europeu; Estados-membros. }\end{array}$ & $\begin{array}{l}\text { Presidência; ministras e ministros } \\
\text { da Defesa, ou seus equivalentes, } \\
\text { dos países da Unasul; delegações } \\
\text { nacionais; instância executiva. }\end{array}$ \\
\hline $\begin{array}{l}\text { Regra } \\
\text { decisória }\end{array}$ & Unanimidade & Unanimidade \\
\hline $\begin{array}{l}\text { Amplitude da } \\
\text { agenda e dos } \\
\text { objetivos }\end{array}$ & $\begin{array}{l}\text { Maior amplitude na agenda, } \\
\text { porém objetivos generalizados e } \\
\text { pouco específicos. }\end{array}$ & $\begin{array}{l}\text { Menor amplitude na agenda, } \\
\text { porém objetivos bem delimitados } \\
\text { e muito específicos. }\end{array}$ \\
\hline $\begin{array}{l}\text { Nível de } \\
\text { convergência } \\
\text { das potências } \\
\text { regionais }\end{array}$ & $\begin{array}{l}\text { Convergência de interesses entre } \\
\text { Reino Unido e França, bem como } \\
\text { da superpotência EUA, que foi } \\
\text { determinante para a cooperação } \\
\text { em defesa. }\end{array}$ & $\begin{array}{l}\text { Convergência de interesses entre } \\
\text { Brasil e Venezuela, bem como } \\
\text { da superpotência EUA, que foi } \\
\text { determinante para a cooperação } \\
\text { em defesa. }\end{array}$ \\
\hline
\end{tabular}

Fonte: elaboração dos autores com dados extraídos do Estatuto do Conselho de Defesa SulAmericano (2008) e do Tratado de Lisboa (2009). 


\section{REFERÊNCIAS}

Abdul-Hak, Ana Patrícia Neves. 2013. O Conselho de Defesa Sul-Americano: objetivos e interesses do Brasil. Brasília: FUNAG.

Acharya, Amitav. 1994. "Regional approaches to security in the Third World: lessons and prospects". In The South at the End of the Twentieth Century: Rethinking the Political Economy of Foreign Policy in Africa, Asia, the Caribbean and Latin America, edited by Timothy Shaw, and Larry Swatuk. London: Palgrave Macmillan UK.

Acharya, Amitav, and Alastir Johnston. 2007. "Comparing regional institutions: an introduction”. In Crafting Cooperation: Regional International Institutions in Comparative Perspective, edited by Amitav Acharya and Alastir Johnston. New York: Cambridge University Press.

Arretche, Marta. 1998. “Tendências no estudo sobre avaliação”. In Avaliação de políticas sociais: uma questão em debate, edited by Elizabeth Melo. São Paulo: Cortez.

Bailes, Alyson J. K. 2008. “The EU and a 'Better World': what role for the European Security and Defence Policy?” International Affairs 84, no. 1.

Barbé, Esther. 2016. "La Estrategia Global de la Unión Europea: el camino del medio”. Revista General de Derecho Europeu no. 40.

Buzan, Barry, e Ole Waever. 2003. Regions and Powers: The Structure of International Security. Cambridge: Cambridge University Press.

Diamint, Rut. 2013. "Regionalismo y posicionamiento suramericano: Unasur y ALBA”. Revista CIDOB d'Afers Internacionals no. 101: 55-79.

Donadio, Marcela. 2010. "El Consejo Sudamericano de Defensa y papel en el desarrollo de la confianza mútua”. In Confianza y Seguridad en América del Sur. Publicación del Consejo de Defensa Suramericano, Quito (outubro). http://www. unasurcds.org/index.php?option $=$ com_content\&view $=$ article $\& i d=85 \% 3$ Acuader nos-de-defensa-no-2-en-america-confianza-y-seguridad del=-sur-\&catid48\%3Apublicaciones \&Itemid=225\&lang=pt.

Eurostat, Gabinete de Estatísticas da União Europeia. https://appsso.eurostat. ec.europa.eu/nui/submitViewTableAction.do.

Ferreira-Pereira, Laura Cristina. 2005. "A Europa da defesa: O fim do limbo”. Nação e Defesa 110, $3^{\text {a }}$ série: 87-127, Lisboa. 
Figueiredo, Marcus Faria, and Argelina Maria Cheibub Figueiredo. 1986. "Avaliação Política e Avaliação de Políticas: Um Quadro de Referência Teórica". In Textos IDESP, no. 15. Mimeo.

Fuccille, Alexandre. 2018. "Brasil e o Conselho de Defesa Sul-Americano (CDS): um balanço de uma década de sua existência”. $11^{\circ}$ Encontro da Associação Brasileira de Ciência Política, Curitiba.

. 2019. "A vacilante atuação brasileira na integração regional: o caso do Conselho de Defesa Sul-Americano". Agenda Política 7: 62-85.

Gaspar, Carlos. 2006. "As três principais potências europeias e a crise transatlântica". Nação e Defesa 113 (Primavera): 21-36.

Gonzalez, Rodrigo Stumpf. 2007. "O Método Comparativo e a Ciência Política". Revista de Estudos e Pesquisas sobre as Américas 1, no. 1.

Henriques, Anna Beatriz, and Thalita Silva. 2019. "A Política Europeia de Segurança e Defesa: avanços e retrocessos pós Tratado de Lisboa". Revista de Estudos Internacionais 10: 102-114.

Howorth, Jolyon. 2017. "The European Union's Security and Defence Policy: The Quest for Purpose". In International Relations and the European Union, edited by Christopher Hill, Michael Smith, and Sophie Vanhoonacker. Oxford: Oxford University Press.

Jobert, Bruno, and Pierre Muller. 1987. L'État en action: Politiques publiques et Corporatismes. Paris: Presses Universitaires de France.

Malamud, Andrés. 2005. "Presidential diplomacy and the institutional underpinnings of Mercosur: an empirical examination". Latin American Research Review 40, no. 1 .

Menon, Anand. 2014. "Defence Policy". In The Oxford Handbook of the European Union, edited by Erik Jones, Anand Menon, and Stephen Weatherill. Oxford: Oxford University Press.

Nolte, Detlef. 2010. "How to compare regional powers: analytical concepts and research topics". Review of International Studies 36: 881-901.

Nye, Joseph. 2008. The Powers to Lead: Soft, Hard and Smart. Oxford: Oxford University Press.

Onuf, Nicholas. 1989. World of our making: rules and rule in social theory and international relations. Columbia: University of South Carolina. 
Pagliari, Graciela de Conti. 2009. O Brasil e a segurança na América do Sul. Curitiba: Juruá.

Palacios Jr, Alberto Montoya Correa, and Laura C. González. 2011a. "Estados falidos e áreas não governadas na América do Sul: caso da fronteira ColombiaEquador". In Fronteiras latino-americanas, Geopolítica do século XXI, edited by Cremilda Medina. São Paulo: Fundação Memorial América Latina/Cátedra Unesco.

. 2011b. "Os desafios da criação do Centro de Estudos Estratégicos da Defesa (CEED-Unasur) e a integração de defesa na América do Sul” In A defesa e a segurança na América do Sul: IV Encontro da ABED, edited by Vágner Camilo Alves, William de Souza Moreira, and Miguel Arias Neto: 59-73. Campinas: Mercado das Letras.

Pereira, Demetrius Cesário. 2012. "A Política Externa e de Segurança Comum da União Europeia após o Tratado de Lisboa: a caminho da supranacionalidade?” Tese (doutorado), Programa de Pós-Graduação em Ciência Política, Universidade de São Paulo.

Przeworski, Adam, and Henry Teune. 1970. Logic of comparative social inquiry. Minnesota: John Wiley \& Sons, Inc.

Saint-Pierre, Héctor Luis. 2009. "La naturaleza política de la Defensa”. In Memórias del Seminário "Modernización de los Ministérios de Defensa". Quito, Equador.

Saint-Pierre, Héctor Luis, and Alberto Montoya Palácios Junior. 2014. "As medidas de confiança no Conselho de Defesa Sul-Americano (CDS): análise dos gastos em Defesa (2009-2012)”. Revista Brasileira de Política Internacional 57, no. 1: 22-39.

Sanahuja, José Antonio. 2016. "Regionalismo e integración en América Latina: de la fractura Atlántico Pacífico a los retos de una globalización en crisis". Pensamiento Propio 21: 29-76.

Sartori, Giovanni. 1994. "Comparación y método comparativo". In La comparación en las ciencias sociales, edited by Giovanni Sartori, and Leonardo Morlino. Madrid: Alianza Editorial.

Schoeman, Maxi. 2003. "South Africa as an Emerging Middle Power: 1994-2003". In State of the Nation: South Africa 2003-2004, edited by John Daniel, Adam Habib, and Roger Southall. Cape Town: HSRC Press.

Serviço Europeu para a Ação Externa - SEAE. 2016b. "Common Security and Defence Policy of the European Union: Missions and Operations Annual Report". 
European Union. https://eeas.europa.eu/sites/eeas/files/e_csdp_annual_report1.pdf.

2018. About EUAM Iraq. European Union. https://eeas.europa.eu/csdp-missions-operations/euam-iraq/33962/about-euam-iraq_en.

Stelzer, Joana. 2001. União Europeia e supranacionalidade: desafio ou realidade? Curitiba, Juruá.

Sweet, Alec Stone, e Wayne Sandholtz. 1997. "European integration and supranational governance". Journal of European Public Policy 4, no. 3.

Teixeira Jr, Augusto W. 2015. "Contribuições do Conselho de Defesa SulAmericano para a Cooperação Militar”. Revista Política Hoje 24, no. 1.

Unasul. 2008. "Decisión para el Establecimiento del Consejo de Defensa Suramericano de la Unasur". Salvador, Brasil.

União Europeia. 2016. “Tratado da União Europeia” (versão consolidada). https:// eur-lex.europa.eu/resource.html? uri=cellar:9e8d 52e 1-2c70-1 1e6-b497-0 1 aa75ed71a1.0019.01/DOC_2\&format=PDF.

Villarroel, Gladys. 2001. "El método comparativo: entre complejidad y generalización”. Revista Venezolana de Ciencia Política 20: 97-120. 


\section{NOTAS}

1. Esse artigo é fruto do projeto Defesa nacional, fronteiras e migrações: estudos sobre ajuda humanitária e segurança integrada, com financiamento do Ministério da Defesa (MD) e da Coordenação de Aperfeiçoamento de Pessoal de Nível Superior (CAPES) e do projeto Cátedra Jean Monnet da UFGD, financiado pela Comissão Europeia. Os autores agradecem o financiamento dos órgãos de fomento.

2. Os dados utilizados nesta afirmação fazem referência ao ano de 2018 e foram disponibilizados pelo Gabinete de Estatísticas da União Europeia, Eurostat. Para mais informações, ver: https://appsso.eurostat.ec.europa.eu/nui/submitViewTableAction.do.

3. “[ $[.$.$] existe um consenso sobre a prioridade das questões de defesa e$ segurança entre a Alemanha, a Grã-Bretanha e a França, formado no processo iniciado com a cimeira bilateral de Saint-Malo, que antecede a crise do pós 11 de setembro. Como é óbvio, essas políticas são o domínio eletivo das grandes potências regionais, as únicas que lhes podem garantir um mínimo de credibilidade através de um consenso trilateral forte" (Gaspar 2006, 35).

4. Esta constatação está baseada na análise dos Planos de Ação que foram publicizados, visto que o último Plano faz referência aos anos de 20142016. Os Planos encontravam-se no site oficial da Unasul, que saiu do ar em setembro de 2019, como resultado da gradual desidratação sofrida pela instituição. Deixaram a iniciativa os seguintes países: Colômbia (em 2018), Chile, Argentina, Paraguai, Brasil, Peru, Equador (em 2019) e Uruguai (em 2020).

5. O termo smart power faz referência à capacidade de combinar hard e soft power de maneira a lograr ganhos positivos (Nye 2008). 


\section{UNASUL E UNIÃO EUROPEIA: ANÁLISE COMPARADA EM TERMOS DE SEGURANÇA E DEFESA}

\section{RESUMO}

Ao se considerar a análise comparada como método ímpar para a compreensão dos mais variados fenômenos - entre eles as dinâmicas do cenário internacional - este trabalho traça um paralelo entre os órgãos de segurança e defesa da UNASUL e da União Europeia, com o intuito de compreender a lógica da cooperação em segurança e defesa no âmbito das instituições regionais. Como problema de pesquisa, busca-se responder ao questionamento sobre o porquê de a cooperação em temas de segurança e defesa representar uma inflexão, visto que as questões ainda encontram travas que impedem seu aprofundamento no nível regional. Para tanto, a pesquisa se atém ao Conselho de Defesa Sul-Americano (CDS) da Unasul, que representa a primeira iniciativa de cooperação em segurança e defesa entre todos os países da América do Sul, e à Política Comum de Segurança e Defesa (PCSD) da União Europeia, que constitui o atual estágio da integração europeia sobre os referidos temas.

Palavras-chave: Conselho de Defesa Sul-Americano; Política Comum de Segurança e Defesa; Instituições Regionais; Cooperação.

\section{ABSTRACT}

Considering the comparative analysis as a unique tool for understanding the most varied phenomena - among them the dynamics of the international scenario - , this paper draws a parallel between Unasur's and the European Union's security and defense organs, in order to understand the logic of cooperation in security and defense within regional institutions. As a research problem, it seeks to answer the question on why cooperation on security and defense issues represents an inflection, as it still faces difficulties that prevent its deepening at regional level. Thus, the investigation examines the Unasur's South American Defense Council, which is the lead cooperation initiative among all South American countries on security and defense, and the European Union's Common Security and Defense Policy, which constitutes the current stage of European integration on these issues.

Keywords: South American Defense Council; Common Security and Defense Policy; Regional Institutions; Cooperation. 